\title{
Polymorphism and genetic control of high molecular weight glutenin subunits in wild tetraploid wheat Triticum turgidum var. dicoccoides
}

\author{
A. A. Levy, \\ G. Galili and \\ M. Feldman
}

Department of Plant Genetics, The Wiezmann

Institute of Science, Rehovot 76 100, Israel.

Polymorphism of the high molecular weight glutenin subunits was studied in 456 accessions of the wild wheat $T$ riticum turgidum var. dicoccoides $(2 n=4 x=28$; genomes AABB), originating from 21 populations in Israel. A total of 50 different SDS PAGE migration patterns were observed, resulting from the combinations of 15 subunit patterns of the A genome and 24 subunit patterns of the B genome. Most migration patterns consisted of five subunits, varying between three and six. The migration patterns of the A genome had zero to three subunits-two being most common. The apparent molecular weights (MWs) of the slowest migrating subunit $(114,000$ to 103,500$)$ and of the next in rate of migration $(106,000$ to 96,000$)$ were highly correlated $(r=0.97)$. Also, both subunits were either present (in most accessions) or absent. In 82.3 per cent of the accessions, the third subunit (MW 76,000 to 71,500) was absent, while in 16.9 per cent of the accessions all three subunits of the $A$ genome were absent. The migration patterns of the $B$ genome had one to three subunits-three being most common. The slowest migrating subunit $(99,500$ to 93,000$)$ was present in almost all cases $(99 \cdot 3$ per cent). The MWs of the next two subunits $(90,500$ to 82,000 and 86,000 to 78,000 , respectively) were highly correlated $(r=0.95)$. Also, either both subunits were present, as in most cases (94.4 per cent), or absent (5.6 per cent). A nomenclature for the genes encoding for the HMW glutenins is proposed based on the following model: The three subunit groups controlled by each genome are encoded by two genes. In genome $A$, one gene (Glu-A1-1), with 12 alleles, encodes for the two correlated subunit groups $1 \mathrm{Ax}$ and $1 \mathrm{Ax}$; the other gene (Glu$A 1-2)$, with 3 alleles, encodes for the fast-migrating subunit group (1Ay). In genome B, one gene (Glu-B1-1), with 8 alleles, encodes for the slow-migrating subunit group (1Bx), and the other gene (Glu-B1-2), with 10 alleles, encodes for the two correlated subunit groups, $1 \mathrm{By}$ and $1 \mathrm{By}^{\prime}$. The polymorphism of the $\mathrm{HMW}$ glutenin genes found in var. dicoccoides is much higher than that of cultivated wheats as well as of genes coding for enzymes in var. dicoccoides.

\section{INTRODUCTION}

The glutenin fraction of the wheat kernel is comprised of aggregates of high molecular weight (HMW) protein subunits, cross-linked by disulfide bonds. This fraction represents $10-40$ per cent of the total endosperm storage proteins and plays an important role in the visco-elastic properties of the flour dough (for a review see Kasarda et al., 1976). In any of the wheat lines a total of about 15 glutenin subunits were identified varying in molecular weight (MW) from 11,000 to 136,000 (Bietz and Wall, 1972; Payne and Corfield, 1979). Among the HMW glutenins (MW above 70,000), specific subunits were related to baking quality (Payne et al., 1979; Payne et al., 1981a).

The HMW glutenins are controlled by the long arms of homoeologous-group-1 chromosomes, as revealed by sodium-dodecyl-sulphate, polyacryl- amide-gel electrophoresis (SDS PAGE) of various aneuploids and intervarietal substitution lines of the common wheat cultivar Chinese Spring (CS) (Bietz et al. 1975; Payne et al. 1982; Galili and Feldman, $1983 a, b)$. The genes encoding for these subunits occur on each of the arms $1 \mathrm{BL}, 1 \mathrm{DL}$ and $1 \mathrm{AL}$ in what has been termed a complex locus (Payne et al., 1982) or a gene cluster (Galili and Feldman, 1983a)-each controlling up to three HMW glutenin subunits. Thus far, the variation in these subunits was described mainly in bread wheat (Payne and Lawrence, 1983; Galili and Feldman, 1983b). It was found that these genes are multiallelic, coding for subunits that vary considerably in their MW (Payne and Lawrence, 1983; Galili and Feldman, 1983b).

In this work the polymorphism of the HMW glutenins, with respect to the allelic variation of the homoeologous genes on $1 \mathrm{AL}$ and $1 \mathrm{BL}$, was 
studied in a wide range of accessions of the wild tetraploid wheat Triticum turgidum var. dicoccoides, $(2 n=4 x=28 ;$ genomes AABB $)$, the immediate progenitor of most cultivated wheats. This polymorphism was compared to that found in cultivated ines.

\section{MATERIALS AND METHODS}

\section{Plant material}

Plants of var. dicoccoides were collected in 1983, 1984 and 1985 from 21 populations representing various habitats in Israel. These habitats range from the Judean mountains in the south to Mount Hermon in the north, and vary sharply in climate, often over short distances: dry $(350 \mathrm{~mm}$ annual rainfall) to rainy habitats $(1300 \mathrm{~mm})$; low altitudes ( $200 \mathrm{~m}$ below sea level) to relatively high elevations ( $1500 \mathrm{~m}$ above sea level); and hot vs. cold temperatures. Var. dicoccoides is restricted to two soil types, basalt and terra rossa. About 20 plants were randomly collected from each population; in total, 456 accessions were studied in this work.

In addition, two durum cultivars, Ld222 (obtained from the University of North Dakota) and Inbar (an Israeli commercial variety), the amphiploid var. dicoccoides-Ae. squarrosa (xx340) and the nullisomic 1D-tetrasomic $1 \mathrm{~B}$ line of the common wheat cultivar Chinese Spring (CS) were also used.

\section{Extraction and fractionation of HMW glutenins}

Following Galili and Feldman (1983a), endosperm protein subunits were extracted from mature kernels that were collected from the wild, using $8 \mathrm{mM}$ Al-lactate, followed by sample buffer solution (consisting of 10 per cent glycerol, 3 per cent SDS, 5 per cent 2-mercaptoethanol and $66 \mathrm{mM}$ Tris- $\mathrm{HCl}, p \mathrm{H} \mathrm{6} \cdot 8)$. Fractionation was carried out in SDS PAGE of 7-12 per cent acrylamide gradients. The samples were run on $13 \mathrm{~cm}$ long gels for $4 \mathrm{~h}$ at a constant voltage of 150 volts.

\section{Estimation of molecular weight}

The molecular weight (MW) of various HMW glutenin subunits was estimated by comparison to the following protein markers (Pharmacia) with the indicated MW: phosphorylase-B $(94,000)$, bovine serum albumin (67,000), ovalbumin $(43,000)$ and carbonic anhydrase $(30,000)$. Samples of the cv. CS were run in each gel for comparison; the MWs of its HMW glutenins were previously described (Galili and Feldman, 1983a). The high- resolution, one-dimensional SDS PAGE enabled us to distinguish differences in apparent $\mathrm{MW}$ as low as 500 . Such differences were confirmed by several gel runs.

\section{RESULTS}

\section{Assignment of subunits to genomes and to chromosome arms}

The SDS PAGE migration pattern of total endosperm proteins of one accession of var. dicoccoides is shown in fig. 1. In this accession, six HMW glutenin subunits are present, each belongs to a particular subunit group. The designation of subunits $1 \mathrm{Bx}$ and $1 \mathrm{By}$ follows that of Payne et al. $(1981 b)$. Subunit $1 \mathrm{By}^{\prime}$ is equivalent to $1 \mathrm{Bz}$ of Holt et al. (1981) and to subunits encoded by the presumed Glt-B3 gene (Galili and Feldman, 1983b). The designation $1 \mathrm{Ax}$ and $1 \mathrm{Ay}$ follows that of Payne et al. (1983); the basis for designating the $1 \mathrm{Ax}^{\prime}$ group is discussed later.

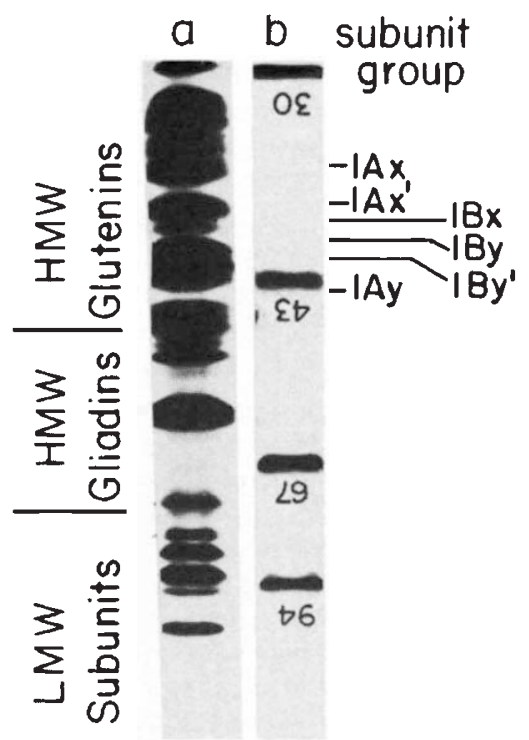

Figure 1 Lane a. SDS-PAGE migration pattern of total endosperm proteins of one accession of var. dicoccoides. Lane b. Protein markers and their MW $(\times 1000)$.

Since previous assignment of subunits to genomes was carried out in hexaploid wheat, several crosses were done to ascertain this assignment on the tetraploid level. Using durum substitution lines nullisomic 1B-disomic 1D (N1BD1D) Orth and Bushuk (1974) showed data indicating that the HMW glutenin genes of the durum cv. 

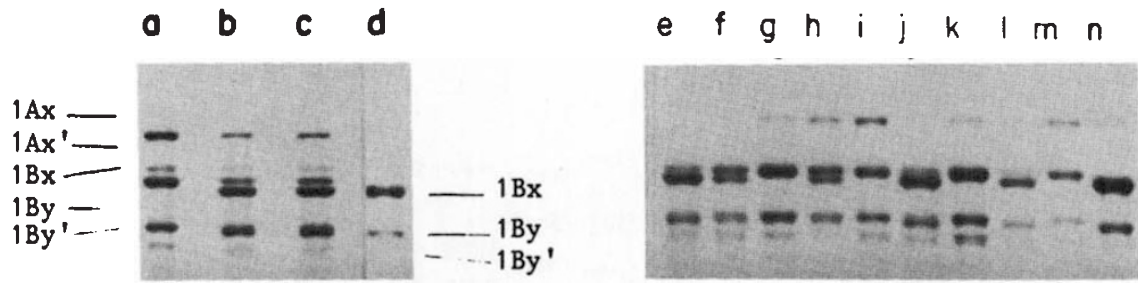

Figure 2 Gel patterns of HMW glutenins from seed progenies of the cross between the tetraploid lines, var. durum $\mathrm{cv}$. Ld $222 \times$ var. dicoccoides (TTD-04). (a) parental line TTD-04; (b,c) $F_{1}$ hybrids; (d) parental line Ld222; (e-n) $F_{2}$ progeny. The designation of the subunit groups is given.

Ld222 are located on chromosome 1B. Based on the segregation of HMW glutenins in $F_{2}$ progeny derived from the cross between cv. Ld222 and an accession of var. dicoccoides (TTD-04) (fig. 2), it was concluded that subunits $1 \mathrm{Bx}, 1 \mathrm{By}$ and $1 \mathrm{By}^{\prime}$ of TTD-04 are allelic to the subunits of Ld222 and therefore are also controlled by chromosome $1 \mathrm{~B}$. In contrast, the subunits $1 \mathrm{Ax}$ and $1 \mathrm{Ax}^{\prime}$ segregated independently of the subunits controlled by $1 \mathrm{~B}$ and were therefore assigned to the homoeologous locus on 1A. The homology between the HMW glutenin loci of another accession of var. dicoccoides (TTD-09) and those of the common wheat cv. CS was confirmed by the $F_{2}$ segregation of the cross between the amphiploid var. dicoccoides (TTD-09)-Ae. squarrosa $(\mathrm{x} \times 340)$ and the nullisomic 1D-tetrasomic 1B (N1DT1B) line of CS. In $\mathrm{xx} 340$, subunits $1 \mathrm{Ax}, 1 \mathrm{Ax}^{\prime}, 1 \mathrm{Ay}, 1 \mathrm{Bx}, 1 \mathrm{By}$ and $1 \mathrm{By}^{\prime}$ were so designated based on their appearance in the tetraploid line TTD-09 (data not shown); subunits $1 \mathrm{Dx}$ and $1 \mathrm{Dy}$ appeared only in the amphiploid and were therefore assigned to genome D (fig. 3(d)). $F_{2}$ analysis of the cross $\times x 340 \times$ N1DT1B indicated that the HMW glutenin genes encoding for $1 \mathrm{Bx}, 1 \mathrm{By}$ and $1 \mathrm{By}^{\prime}$ of var. dicoccoides are located on the long arm of chromosome $1 \mathrm{~B}$ (1BL). In addition, subunits $1 \mathrm{Ax}, 1 \mathrm{Ax}^{\prime}$ and $1 \mathrm{Ay}$ of $x \times 340$ co-segregated, independently of the segregation of subunits controlled by $1 \mathrm{BL}$, thus indicating their control by $1 \mathrm{~A}(1 \mathrm{AL})$. The control of subunits $1 \mathrm{Ax}, 1 \mathrm{Ax}^{\prime}$ and $1 \mathrm{Ay}$ by chromosome $1 \mathrm{~A}$ and of $1 \mathrm{Bx}, 1 \mathrm{By}$ and $1 \mathrm{By}$ 'by chromosome $1 \mathrm{~B}$

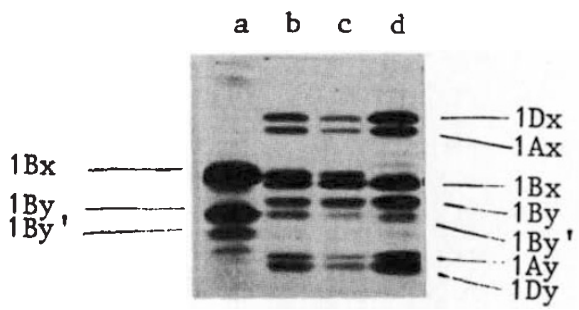

was also confirmed by several other crosses between vars. durum and dicoccoides (data not shown). In accord with the above, subunits $1 \mathrm{Bx}$, $1 \mathrm{By}$ and $1 \mathrm{By}^{\prime}$ had the same range of $\mathrm{MW}$ as described for the HMW glutenins of $1 \mathrm{BL}$ in common wheat (Galili and Feldman, 1983b, 1985a), while subunits $1 \mathrm{Ax}, 1 \mathrm{Ax}^{\prime}$ and $1 \mathrm{Ay}$ had the same range of $\mathrm{MW}$ as described in common wheat for the A genome (Galili and Feldman, 1983b, 1985a) and as described in the diploid donor of the $A$ genome (Galili and Feldman, 1983c).

\section{Polymorphism of the HMW glutenin subunits}

The SDS PAGE migration patterns of endosperm proteins from a representative sample of 456 accessions of var. dicoccoides, originating from 21 populations in Israel are presented in fig. 4 . A wide range of variation in these proteins is clearly evident.

The various migration patterns of $\mathrm{HMW}$ glutenins controlled by the A genome were arranged in an ascending order of MW of subunits of the 1Ax group (fig. 5). Twelve different subunits were found in this subunit group, ranging in $\mathrm{MW}$ from 114,000 to 103,500 ; 9 subunits were found in the group $1 \mathrm{Ax}^{\prime}$, ranging in $\mathrm{MW}$ from 106,000 to 96,000; and 3 subunits were found in group 1 $\mathrm{Ay}^{\prime}$, ranging from 76,000 to 71,500 . These subunits formed 15 different band patterns, $A_{1}$ to $A_{15}$. In mosi patterns, subunit group 1 Ay was absent, and the pattern lacking altogether the three subunit

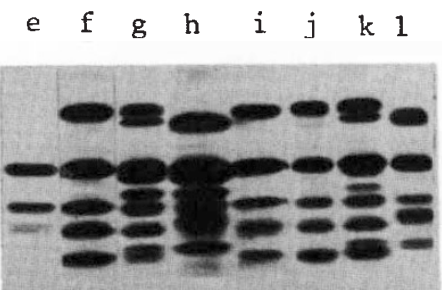

Figure 3. Gel patterns of HMW glutenins derived from: (d) the hexaploid amphiploid " $\mathrm{x} \times 340$ " produced by the cross var. dicoccoides (TTD-09) $\times$ Ae. squarrosa; (a) nullisomic 1D-tetrasomic 1B (N1DT1B); (b,c) F progeny of N1DT1B “"xx340"; (e-1) several $\mathrm{F}_{2}$ patterns of the cross N1DT1B $\times$ " $\times \times 340$ ". The designation of the subunit groups is given. 


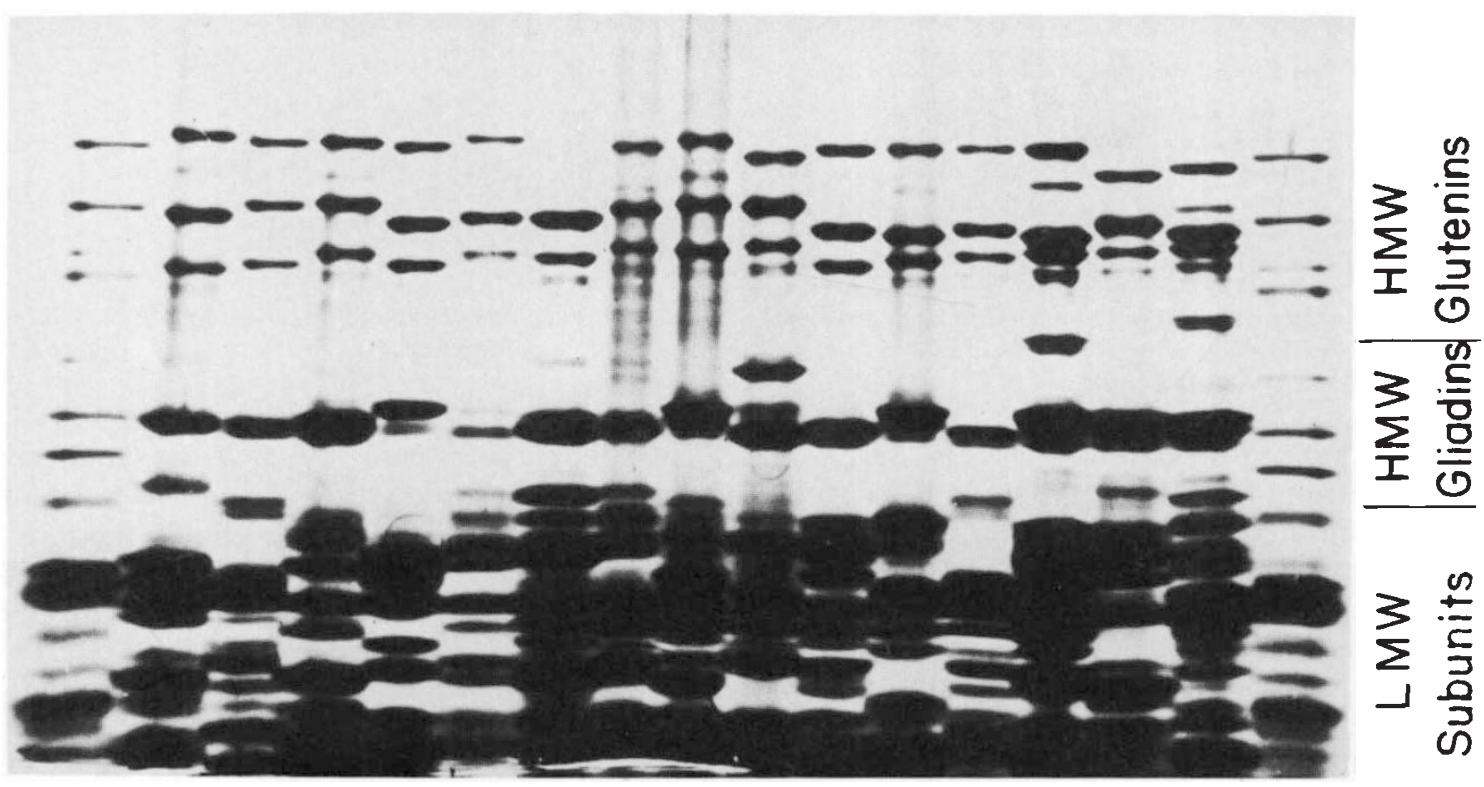

Figure 4 SDS-PAGE migration pattern of total endosperm proteins of various accessions of var. dicoccoides. The pattern of the cultivar Chinese Spring is shown in the first and last lanes.

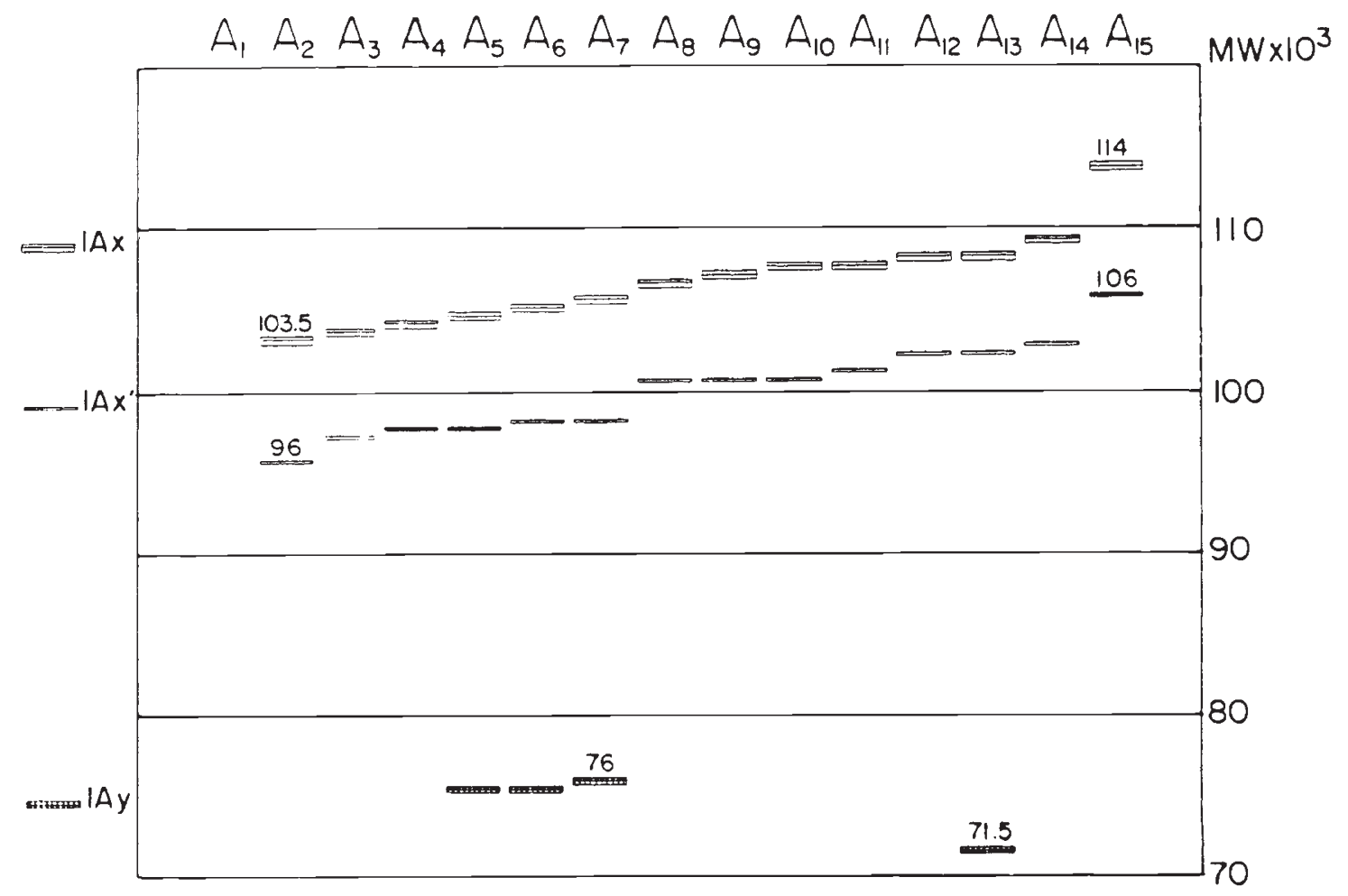

Figure 5 The various types of subunit patterns $\left(A_{1}\right.$ to $\left.A_{15}\right)$ of the HMW glutenins of the $A$ genome found in 456 accessions of var. dicoccoides. 
groups of the A genome (pattern A1) occurred relatively frequently (16.9 per cent) (table 1$)$. Invariably, subunits of groups $1 \mathrm{Ax}$ and $1 \mathrm{Ax}^{\prime}$ segregated together. The correlation between the MWs of these subunits was almost complete $(r=0.97)$, and highly significant $\{p(r)<0.001\}$ : invariably, the slowly-migrating subunit of $1 \mathrm{Ax}$ appeared with the slowly-migrating subunit of $1 \mathrm{Ax}^{\prime}$, and similarly, the rapidly-migrating subunits of these groups always co-appeared. The differences between their MWs varied from 6000 to 8000 . Invariably, subunits of group $1 \mathrm{Ax}$ formed a wide band, while subunits of $1 \mathrm{Ax}^{\prime}$ were faint. The variation in $\mathrm{MW}$ of subunits of group $1 \mathrm{Ay}$ was not related to that of subunits of $1 \mathrm{Ax}$ or $1 \mathrm{Ax}^{\prime}$.

The migration patterns of subunits controlled by the $\mathrm{B}$ genome were arranged in an ascending order of MWs of subunit of the 1By group (fig. 6). Eight different subunits were found in group $1 \mathrm{Bx}$, ranging in MW from 99,500 to 93,$000 ; 10$ subunits were found in group $1 \mathrm{By}$, ranging from 90,500 to 82,000 and 12 subunits were found in group $1 \mathrm{By}^{\prime}$, ranging in $\mathrm{MW}$ from 86,000 to 78,000 . These subunits formed 24 different band patterns, $B_{1}$ to $B_{24}$. Patterns having fewer than 3 subunits were infrequent (see table 1). However, when inactiva- tion occurred, it affected either both $1 \mathrm{By}$ and $1 \mathrm{By}^{\prime}$ (patterns $\mathrm{B}_{1}$ to $\mathrm{B}_{5}$ ) or $1 \mathrm{Bx}$ alone (pattern $\mathrm{B}_{17}$ ), but not the three subunits together. Similarly to the correlation between $1 \mathrm{Ax}$ and $1 \mathrm{Ax}^{\prime}$ there was a high positive correlation between the MWs of subunits of groups $1 \mathrm{By}$ and $1 \mathrm{By}^{\prime}\{r=0.95 ; p(r)<0.001\}$ and the difference between the MWs of subunits $1 \mathrm{By}$ and $1 \mathrm{By}^{\prime}$ varied from 4000 to 8000 ; the correlations between the MWs of subunits of the $1 \mathrm{Bx}$ group and subunits of $1 \mathrm{By}$ and $1 \mathrm{By}^{\prime}$ was low and nonsignificant $(r=0 \cdot 11$ and $0 \cdot 01$, respectively). Invariably, subunits of group 1By formed a wide band, while those of $1 \mathrm{By}^{\prime}$ were narrow and faint.

The number of band patterns of genome B (24) was much lower than that expected from a random associaton between alleles of $1 \mathrm{Bx}$ and $1 \mathrm{By}$. Similarly, the number of patterns of genome A (15) was lower than expected from a random association between $1 \mathrm{Ax}$ and $1 \mathrm{Ay}$, though this is somewhat confounded by the lack of expression of 1 Ay in most patterns. These findings are in accord with the genetic linkage between the $\mathrm{x}$ and $y$ genes of each chromosome.

The frequencies of the various patterns of the $\mathrm{A}$ and $\mathrm{B}$ genomes, expressed as percentage of the 456 accessions studied, are presented in table 1 .

Table 1 Frequencies of combinations of the 15 band patterns of the A genome and the 24 band patterns of the B genome, expressed as percentage of the 456 accessions studied. The total frequency of the A and B genomes patterns is given too.

\begin{tabular}{|c|c|c|c|c|c|c|c|c|c|c|c|c|c|c|c|c|}
\hline & $\mathrm{A}_{1}$ & $\mathrm{~A}_{2}$ & $\mathrm{~A}_{3}$ & $\mathrm{~A}_{4}$ & $\mathrm{~A}_{5}$ & $\mathrm{~A}_{6}$ & $A_{7}$ & $\mathrm{~A}_{8}$ & $\mathrm{~A}_{9}$ & $\mathrm{~A}_{10}$ & $A_{11}$ & $\mathrm{~A}_{12}$ & $\mathrm{~A}_{13}$ & $\mathrm{~A}_{14}$ & $\mathrm{~A}_{15}$ & $\begin{array}{l}\text { Total B } \\
\text { patterns }\end{array}$ \\
\hline$B_{1}$ & & & & & & & & & & 0.2 & & & & & & $0 \cdot 2$ \\
\hline $\begin{array}{l}\mathrm{B}_{2} \\
\mathrm{~B}_{3}\end{array}$ & & 1.4 & & & & & & & & & & $0 \cdot 1$ & & $0 \cdot 1$ & & 1.6 \\
\hline $\begin{array}{l}\mathrm{B}_{3} \\
\mathrm{~B}_{4}\end{array}$ & & & & & & & & & & & $3 \cdot 2$ & & & & & $3 \cdot 2$ \\
\hline $\begin{array}{l}\mathrm{B}_{4} \\
\mathrm{~B}_{5}\end{array}$ & & 0.2 & & & & & & & & 0.2 & & & & & & 0.4 \\
\hline $\begin{array}{l}\mathrm{B}_{5} \\
\mathrm{~B}_{6}\end{array}$ & & & & & & 0.2 & & & & & & & & & & 0.2 \\
\hline $\begin{array}{l}\mathrm{B}_{6} \\
\mathrm{~B}_{7}\end{array}$ & & & & & $4 \cdot 1$ & & & & & & & & & 2.6 & & $6 \cdot 7$ \\
\hline $\begin{array}{l}\mathrm{B}_{7} \\
\mathrm{~B}_{8}\end{array}$ & $4 \cdot 8$ & & & & & & & & & 0.2 & & & & & & $5 \cdot 0$ \\
\hline $\begin{array}{l}\mathrm{B}_{8} \\
\mathrm{~B}_{9}\end{array}$ & & & & & & & & & & & & & & 0.2 & & 0.2 \\
\hline $\begin{array}{l}\mathrm{B}_{9} \\
\mathrm{~B}_{10}\end{array}$ & & 1.6 & & & & & & & & 0.3 & & & & & & 1.9 \\
\hline $\begin{array}{l}\mathrm{B}_{10} \\
\mathrm{~B}_{1}\end{array}$ & & & & & & & & & & $4 \cdot 8$ & & & & & & $4 \cdot 8$ \\
\hline $\mathrm{B}_{11}$ & & & 0.2 & & & & & & & $2 \cdot 5$ & & & & 0.2 & & $2 \cdot 9$ \\
\hline $\begin{array}{l}\mathrm{B}_{12} \\
\mathrm{~B}_{13}\end{array}$ & & & 4.8 & & & & & & & & & & & & & $4 \cdot 8$ \\
\hline $\begin{array}{l}\mathrm{B}_{13} \\
\mathrm{~B}_{14}\end{array}$ & 0.8 & & & & & & & & & 1.4 & & & & $4 \cdot 5$ & 0.3 & $7 \cdot 0$ \\
\hline $\begin{array}{l}\mathrm{B}_{14} \\
\mathrm{~B}_{15}\end{array}$ & & 0.3 & & & & & & & & 0.4 & & & & & & 0.7 \\
\hline $\begin{array}{l}\mathrm{B}_{15} \\
\mathrm{~B}_{16}\end{array}$ & & 0.6 & & & & & $4 \cdot 8$ & & 5.4 & $5 \cdot 2$ & & $4 \cdot 6$ & & 1.4 & & 21.9 \\
\hline $\begin{array}{l}\mathrm{B}_{16} \\
\mathrm{~B}_{17}\end{array}$ & & & & & & & & & & & & & & 1.5 & & 1.5 \\
\hline $\begin{array}{l}\mathrm{B}_{17} \\
\mathrm{~B}_{18}\end{array}$ & & & & & & & & & & 0.7 & & & & & & 0.7 \\
\hline $\begin{array}{l}\mathrm{B}_{18} \\
\mathrm{~B}_{19}\end{array}$ & $9 \cdot 7$ & & & & $5 \cdot 5$ & 1.5 & & & & $2 \cdot 3$ & & & & & & $19 \cdot 0$ \\
\hline $\begin{array}{l}\mathrm{B}_{19} \\
\mathrm{~B}_{20}\end{array}$ & & & & & & & & & & 0.1 & & $4 \cdot 8$ & 1.4 & & & $6 \cdot 3$ \\
\hline $\mathrm{B}_{20}$ & & $1 \cdot 3$ & & & & & & & & & & 0.3 & & 0.1 & & 1.7 \\
\hline $\mathrm{B}_{21}$ & & & & & & & & & & 2.5 & & & & & & 2.5 \\
\hline$B_{22}$ & 1.6 & & & $0 \cdot 1$ & & & & & & 0.5 & & & & & & $2 \cdot 2$ \\
\hline $\mathrm{B}_{23}$ & & & & & & & & $4 \cdot 3$ & & & & & & & & $4 \cdot 3$ \\
\hline $\mathrm{B}_{24}$ & & & & & & 0.2 & & & & & & & & & & 0.2 \\
\hline
\end{tabular}




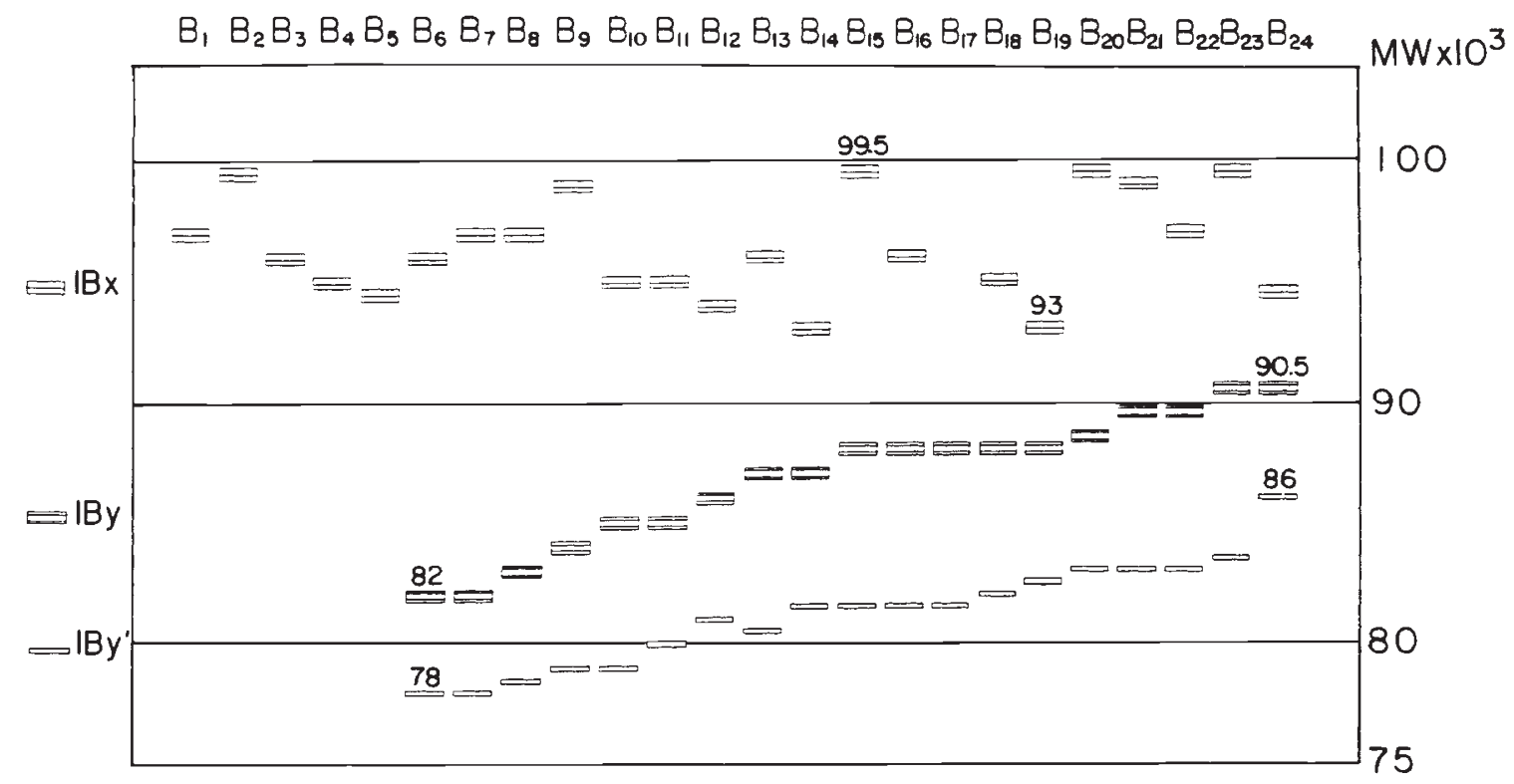

Figure 6 The various types of subunit patterns $\left(B_{1}\right.$ to $\left.B_{24}\right)$ of the HMW glutenins of the $B$ genome found in 456 accessions of var. dicoccoides.

This table also shows the frequency of combinations between the patterns of the $\mathrm{A}$ and $\mathrm{B}$ genomes. A total of 50 different migration patterns were found, resulting from combinations of subunits of the $\mathrm{A}$ and $\mathrm{B}$ genomes. Some patterns, like $\mathrm{A}_{10}$ or $B_{15}$, occurred in a high frequency and participated in many combinations, while others, like $A_{4}, A_{15}$, $B_{1}, B_{8}$ and $B_{24}$, were found in only one population.

\section{DISCUSSION}

\section{The number and chromosomal allocation of the HMW glutenin genes}

The HMW glutenin genes of var. dicoccoides coding for subunits $1 \mathrm{Bx}, 1 \mathrm{By}$ and $1 \mathrm{By}^{\prime}$ were found to be located on the long arm of chromosome 1B, at an allelic locus to that of $1 \mathrm{BL}$ of common wheat and to that of the durum cultivar Ld222. The genes coding for subunits $1 \mathrm{Ax}, 1 \mathrm{Ax}^{\prime}$ and $1 \mathrm{Ay}$ segregated in all crosses independently of $1 \mathrm{Bx}, 1 \mathrm{By}$ and $1 \mathrm{By}^{\prime}$ and were therefore assigned to the homoeologous arm 1AL. This chromosomal assignment is further supported by the range of MW of these subunits, as found in hexaploid and diploid wheats (Galili and Feldman, 1983b,c). Various lines of evidence, including hybridisation with DNA probes (Harberd et al., 1986), N-terminal amino acid sequence analysis (Shewry et al., 1984), intra-cluster recombination (Payne et al., 1983), analysis of struc- tural homology based on amino acid composition and peptide mapping (Galili and Feldman, 1985b), and the patterns of subunit combinations (Galili and Feldman, 1983b) indicated that subunits $1 \mathrm{Bx}$ and $1 \mathrm{By}$ in common wheat are encoded by two different genes. The presented data support this conclusion on the tetraploid level: In several patterns (fig. 6, $\mathrm{B}_{1}$ to $\mathrm{B}_{5}$ ), $1 \mathrm{Bx}$ was expressed while $1 \mathrm{By}$ was absent, and in one pattern (fig. 6, $\mathrm{B}_{17}$ ) $1 \mathrm{By}$ was expressed while $1 \mathrm{Bx}$ was absent. This conclusion is also supported by the occurrence of "recombinant" patterns (compare patterns $\mathrm{B}_{14}$ and $B_{16}$ to $B_{13}$ and $B_{19}$ in fig. 6).

Subunit group $1 \mathrm{By}^{\prime}$ was discovered by Holt et al. (1981), using two-dimensional fractionation, and was designated $1 \mathrm{Bz}$. Galili and Feldman $(1983 b)$ referred to it as the product of a presumed third gene Glt-B3. Being a faint band, which in hexaploid wheat often comigrates with subunits of genome D, it was somewhat ignored in cultivated wheats compared to $1 \mathrm{Bx}$ and $1 \mathrm{By}$. Subunit groups $1 \mathrm{By}$ and $1 \mathrm{By}^{\prime}$ show a great similarity, as inferred from their associated mobility in two-dimensional gels (Holt et al., 1981) and from their amino acid composition and patterns of protease digests (Galili and Feldman, 1985b). It was suggested (Holt et al., 1981), that these subunits are either products of the same gene, or alternatively, products of a recent duplication of an ancestral gene.

The lack of genome $\mathrm{D}$ in var. dicoccoides enabled us to study $1 \mathrm{By}^{\prime}$ on a much wider scale 
than previously studied in common wheat, even in one-dimensional gels. Our data strongly indicate that subunit groups $1 \mathrm{By}$ and $1 \mathrm{By}^{\prime}$ are controlled by a single gene: in all patterns, the two subunits were either present or absent; inactivation, which is a common phenomenon in HMW glutenins, never affected only one of these subunit groups. These subunit groups also showed a strong correlation in MW; were they encoded by two different genes, their allelic variations should not have been related.

That one gene produces two polypeptides could be accounted for by various molecular mechanisms. The 1 By gene may carry two codons of initiation, or of termination, either for transcription or translation. The phenomenon could also result from differential splicing of introns in the mRNA of the gene controlling $1 \mathrm{By}$, as reported for other genes (Rozek and Davidson, 1986). Yet, recently an alpha gliadin gene was shown not to include introns (Anderson et al., 1984), and isolated HMW glutenin genes were shown to be devoid of introns (Forde et al., 1985; Thompson et al., 1985; Sugiyama et al., 1985). 1 By' might also result from an in vivo, or an in vitro (during the extraction process) proteolytic digestion of the $1 \mathrm{By}$ subunit, as was found in wheat-leaf-protein subunits (Colas des Francs et al., 1985). However, our finding (unpublished data) that subunit $1 \mathrm{By}^{\prime}$ persists even when protein extraction was carried out in the presence of various protease inhibitors seems to exclude an in vitro digestion. $1 \mathrm{By}^{\prime}$ may also result from a post-translational modification (phosphorylation, glycosylation or acetylation) of $1 \mathrm{By}$.

The HMW glutenins encoded by the A genome have been studied to a much lesser extent, their genes not being usually expressed in cultivated wheats (Galili and Feldman, 1983c; Thompson et al., 1983; Forde et al., 1985). It may therefore be assumed that in patterns lacking subunits $1 \mathrm{Ax}$, $1 \mathrm{Ax}^{\prime}$ and $1 \mathrm{Ay}$ the genes coding for them were present but inactive. The $1 \mathrm{Ax}$ subunit group was observed in a small number of hexaploid cultivars (Galili and Feldman, 1983 b; Payne and Lawrence, 1983). The 1Ay subunit was found in the diploid T. monococcum (genome AA) and in var. dicoccoides (Galili and Feldman, 1983c). It is shown in this work (fig. 5) in patterns $A_{5}, A_{6}, A_{7}$ and $A_{13}$.

The subunit group $1 \mathrm{Ax}^{\prime}$ (fig. 5) was reported by Galili and Feldman $(1983 b)$ in two band patterns of genome A of hexaploid wheat, and the gene coding it was designated Glt-A2. In our view, following the same reasoning previously presented for the genetic control of subunits groups of the
$\mathrm{B}$ genome, $1 \mathrm{Ax}^{\prime}$ and $1 \mathrm{Ax}$ are probably products of the same gene. Similarly to $1 \mathrm{By}$ and $1 \mathrm{By}^{\prime}$, subunits of these groups were correlated in their MWs and both were either expressed or silenced.

It is assumed that in patterns in which $1 \mathrm{Ay}$ subunit was not expressed, the gene coding for it was present but inactive, as found in cultivated wheats (Thompson et al., 1985; Forde et al., 1985). Thus, the number of different HMW glutenin genes in each genome seems to be only two--one coding for the $\mathrm{x}$ and the other for the $\mathrm{y}$ group. The origin of the $1 \mathrm{Ax}^{\prime}$ and $1 \mathrm{By}^{\prime}$ subgroups should be further investigated.

\section{Nomenclature}

A nomenclature for genes that code for the HMW glutenin subunits was proposed by Payne et al. (1982) and Galili and Feldman (1983b). Payne et al. (1982) designated the gene complex loci in hexaploid wheat $G l u-A 1, G l u-B 1$ and $G l u-D 1$; the alleles at each locus, i.e., the different subunit patterns, each referring to a stock of standard cultivars, were named by the gene cluster designation followed by Latin letters: Glu-B1a, Glu-B1b, etc. (Payne and Lawrence, 1983). These authors, however, did not refer to the genes within a cluster. Galili and Feldman (1983 $b$ ) assumed three genes within each gene cluster of the A and B genomes, designating them by their gene-cluster symbol ( Glt$A$ or Glt-B) followed by an Arabic number: Glt$A 1$, Glt-A2, Glt-A3 and Glt-B1, Glt-B2 and Glt$B 3$, respectively. This nomenclature, in conflict with the evidence brought above, indicates three genes in each gene cluster and erroneously implies homoeology between subunits of Glt-A2 and Glt$B 2$. In light of the above, we propose the following nomenclature for tetraploid wheat: Payne's designation of gene clusters, being commonly used, should be accepted, namely, Glu-A1 and Glu-B1. The genes within a cluster should be named by the gene cluster designation followed by Arabic numbers: Glu-A1-1, Glu-A1-2, Glu-B11 and $G l u-B 1-2$; these genes encode, respectively, for subunit groups $1 \mathrm{Ax}, 1 \mathrm{Ay}, 1 \mathrm{Bx}$ and $1 \mathrm{By}$. Component gene alleles would be designated by lower case Roman letters, i.e., the 12 alleles of Glu-A1-1 are Glu-A1-1a through $l$; the 3 alleles of Glu-A1-2 are $G l u-A 1-2 a$ through $c$; the 8 alleles of Glu-B1-1 are $G l u-B 1-1 a$ through $h$; and the 10 alleles of Glu-B1-2 are Glu-B1-2a through $j$. A complete list of these alleles, including their MWs, the accessions in which they were first found and their cross reference to the known alleles of durum and common wheat is in preparation. Further poly- 
morphism may be detected among alleles encoding subunits of the same MW, based on protein charge, hydrophobicity or sequencing, or at the DNA level, based on restriction sites, or sequencing. However, variation in $\mathrm{MW}$ is the simplest evidence for allelic variation. Such alleles may be termed "MW alleles". It should be considered whether patterns (e.g. fig. $4, \mathrm{~B}_{10}$ and $\mathrm{B}_{11}$ ) or alleles that differ only in the $\mathrm{Ax}^{\prime}$ or the $\mathrm{By}^{\prime}$ subunit (e.g., fig. 4 subunits $\mathrm{By}$ and $\mathrm{By}^{\prime}$ in patterns $\mathrm{B}_{17}, \mathrm{~B}_{18}$ and $\mathrm{B}_{19}$ ) should be designated differently.

\section{Polymorphism}

Although Israel is a center of variation of var. dicoccoides (Feldman, 1977), the variability in the HMW glutenins described in this work might reflect only a small fraction of that present in the whole geographical distribution of this species. The polymorphism of the HMW glutenins, as of any other subunits controlled by gene clusters, can be brought about by the following: (a) the number of active genes within a gene cluster; (b) the number of alleles of each active gene; (c) the combination of the different alleles of active genes of the same genome, resulting in different band patterns; recombinations which are known to occur at a very low frequency (1/1000) (Payne et al., 1983) might further increase the number of combinations involving a given allele. (d) the combination of different genomic patterns.

Obviously, a drastic inactivation of genes reduces the potential for polymorphism. Indeed, Glu-A1-2, which is strongly inactivated, being expressed in 18 per cent of the accessions, has only three alleles. However, a positive relationship was observed between the degree of inactivation and polymorphism: Glu-A1-1 had 12 alleles, $G l u-B 1-2$ had 10 alleles, and Glu-B1-1 had 8 alleles, while as seen in table 1 , the degree of inactivation was, respectively, 16.9 per cent (see pattern $A_{1}$ in fig. 5), 5.6 per cent (see patterns $B_{1}$ to $B_{5}$ in fig. 6) and 0.7 per cent (see pattern $B_{17}$ in fig. 6 ). It may be that storage protein genes which show a tendency for inactivation are under a weaker selection pressure and thus exhibit a higher allelic variation. Inactivation via point mutations can generally occur in high frequency in storage protein genes in view of their high content of glutamine codons (CAA and CAG) that may easily shift to stop codons (TAA and TAG) (Heidecker and Messing, 1986). As discussed by Galili and Feldman $(1983 c)$, gene inactivation affected mainly the HMW glutenin genes of the A genome. In culti- vated wheats, the number of active HMW glutenin genes for genome A varies from 0 to 1 , being mostly 0 , while in var. dicoccoides (fig. 3 ), it varies from 0 to 2 , being in most cases one $(G l u-A 1-1)$. Both in cultivated wheats and in var. dicoccoides the number of active HMW glutenin genes of genome $\mathrm{B}$ varies from 1 to 2 , being in most cases two.

The number of alleles of each active gene was higher in var. dicoccoides than in cultivated wheats: We found in the wild wheat 12 alleles for Glu-A1-1, 3 for Glu-A1-2, 8 for Glu-B1 - 1, and 10 for Glu-B12 , versus $3,0,5$ and 5 alleles, respectively, in cultivated wheats (Galili and Feldman, 1983b).

At the gene-cluster level, polymorphism stems from the number of combinations between the various alleles of active genes. For genome $\mathrm{A}$, we found 15 band patterns in var. dicoccoides versus 3 reported in cultivated hexaploid wheat (Galili and Feldman, 1983b). This strong decrease in polymorphism following cultivation is a result of selection for types that underwent gene inactivation. For genome B, 24 band patterns were found in var. dicoccoides versus 15 described in cultivated wheats (Galili and Feldman, 1983b). In genome $\mathrm{B}$, the total number of possible combinations between the alleles of Glu-B1-1 and those of Glu$B 1-2$ is $8 \times 10=80$ in var. dicoccoides, and $5 \times 5=25$ in cultivated wheats. Twenty-four band patterns were found in var. dicoccoides out of the possible 80 , whereas in cultivated wheats, 15 out of the possible 25 patterns were reported (Galili and Feldman $1983 \mathrm{~b}$ ). Thus, the frequency of combined patterns is lower in the wild $(24: 80)$ than in cultivated material $(15: 25)$, suggesting that more recombinations occurred in cultivated germplasm than in natural populations. Hence, the higher polymorphism at the level of the $G l u-B 1$ gene cluster in var. dicoccoides results from the higher number of alleles per locus rather than from recombination of the various alleles of the two genes.

Ultimately, the polymorphism of HMW glutenins is expressed by combinations of patterns of different genomes. We found 50 different patterns resulting from combinations between band patterns of both genomes; their nature and frequencies are shown in table 1 . The higher number of active genes in the A genome of var. dicoccoides, as compared to cultivated wheats, provided in the former a higher potential for combinations between the Glu-A1 and Glu-B1 patterns.

It should be noted that all band patterns described in cultivated wheats (Galili and Feldman, 1983b) are present in var. dicoccoides, while many band patterns that are present in var. dicoc- 
coides (especially of the A genome) are not found in the cultivated germplasm. This genetic erosion might have come about due to modern breeding practices, as suggested by Feldman and Sears (1981). It was also exemplified by Branlard and Le Blanc (1985), who showed a strong decrease in polymorphism of HMW glutenins in French durum and aestivum cultivars during the last 30 years.

The number of alleles per HMW glutenin gene reported in this work is much higher than that reported for other genes of wild wheat. Allelic variation was studied in var. dicoccoides for genes encoding enzymes (Nevo et al., 1982): Fifteen loci out of the 50 studied were monomorphic and in the 35 polymorphic loci the number of alleles per locus was usually two; only esterases were more polymorphic, with up to six alleles per locus. These two types of genes, i.e., genes coding for storage proteins and those coding for enzymes, also exhibit striking differences in regard to genetic inactivation. Whereas HMW glutenin genes became inactive in a relatively high frequency (Galili and Feldman, 1983c; Galili et al., 1987), there were only rare cases of silencing of enzyme genes of either of the two genomes (Hart 1983). Thus, enzyme genes, which were rarely inactivated, showed a small degree of polymorphism. This is consistent with the previously mentioned positive relationship between the frequency of inactivation and polymorphism in the HMW glutenin genes.

The wide polymorphism described here, particularly subunits that are unique to wild wheats, should be evaluated for their effect on nutritional as well as technological qualities. It has been previously suggested to widen the range of variation of HMW glutenins in cultivated wheats by exploiting the alien species Aegilops umbellulata (Law and Payne, 1983) and Ae. speltoides (Moonen and Zeven, 1985). Yet this approach is difficult because of the reduced homology between the wheat and alien chromosomes. On the other hand, chromosomes of var. dicoccoides show regular pairing with those of cultivated tetraploid wheat (var. durum) and with those of genomes $\mathrm{A}$ and $\mathrm{B}$ of hexaploid wheat ( $T$. aestivum). Therefore, each HMW glutenin subunit of var. dicoccoides can be easily transferred and studied in a cultivated background.

Acknowledgements We are grateful to Mr Y. Avivi for his help during the preparation of the manuscript, to Mrs Ronit Zamir and Mrs Dorit Braun for their help in collecting the material and to Mrs Jeanine Alpay and Mrs Judith Tischel for their technical assistance.

\section{REFERENCES}

ANDERSON, O. D., LITTS, J. C., GAUTIER, M.-F. AND GREENE, F. C. 1984. Nucleic acid sequence and chromosome assignment of a wheat storage protein gene. Nucleic Acids Research 12, 8129-8144.

BIETZ, J. A. AND WALL, J. S. 1972. Wheat gluten subunits: molecular weights determined by sodium dodecyl sulfatepolyacrylamide gel electrophoresis. Amer. Assoc. Cereal Chemists, Inc., 49, 416-430.

BIETZ, J. A., SHEPHERD, K. A. AND WALl, J. S. 1975, Singlekernel analysis of glutenin: use in wheat genetics and breeding. Amer. Assoc. Cereal Chemists, Inc., 52, 513-532.

BRANLARD, G. AND LE BLANC, A. 1985. Les sous-unites glutenines de haut poids moleculaire des bles tendres et des bles durs cultives en France. Agronomie, 5, 467-477.

COLAS DES FRANCS, C., THIELLEMENT, H. AND DE VIENNE, D. 1985. Analysis of leaf proteins by two-dimensional gel electrophoresis Plant Physiol., 78, 178-182.

FELDMAN, M. AND SEARS, E. R. 1981. The wild gene resources of wheat. Scientific American, 244, 102-112.

FELDMAN, M. 1977. Historical aspects and significance of the discovery of wild wheats. Stadler Symp., University of Missouri, Columbia, 9, 121-145.

FORDE, J., MALPICA, J.-M., HALFORD, N. G., SHEWRY, P. R., ANDERSON, O. D., GREENE, F. C. AND MIFLIN, B. J. 1985. The nucleotide sequence of a HMW glutenin subunit gene located on chromosome $1 \mathrm{~A}$ of wheat (Tricum aestivum L). Nucleic Acids Research, 13, 6817-6832.

GALILI, G. AND FELDMAN, M. 1983a. Genetic control of endosperm proteins in wheat. 1. The use of high resolution one-dimensional gel electrophoresis for the allocation of genes coding for endosperm protein subunits in the common wheat cultivar Chinese Spring. Theor. Appl. Genet. $64,97-101$

GALILI, G. AND FELDMAN, M. 1983b. Genetic control of endosperm proteins in wheat. 2. Variation in high molecular weight glutenin and gliadin subunits of Triticum aestivum. Theor. Appl. Genet., 66, 77-86.

GALILI, G. AND FELDMAN, M. 1983c. Diploidization of endosperm protein genes in polyploid wheats. Proc. 6th Int. Wheat Genet. Symp., Kyoto, Japan, pp. 1119-1123.

GALILI, G. AND FELDMAN, M. 1985a. Genetic control of endosperm proteins in wheat. 3. Allocation to chromosomes and differential expression of high molecular weight glutenin and gliadin genes in intervarietal substitution lines of common wheat. Theor. Appl. Genet., 69, 583-589.

GALILI, G. AND FELDMAN, M. 1985b. Structural homology of endosperm high molecular weight glutenin subunits of common wheat (Triticum aestivum L.) Theor. Appl. Genet., $70,634-642$.

GALIL1, G. LEVY, A. A. AND FELDMAN, M. 1987. Diploidization of genes coding for high molecular weight glutenins in tetraploid wheat. Evolution (submitted).

HARBERD, N. P., BARTELS, D. AND THOMPSON, R. D. 1986. DNA restriction-fragment variation in the gene family encoding high molecular weight (HMW) glutenin subunits of wheat. Biochemical Genet. 24, 579-596.

HART, G. E. 1983. Hexaploid wheat (Triticum aestivum L. em Thell). In Tanksley, S. D. and Orton, T. J. (eds), Isozymes in Plant Genetics and Breeding, Part B, Elsevier Science Publishers, B. V., Amsterdam, pp. 35-56.

HEIDECKER, G. AND MESSING, J. 1986. Structural analysis of plant genes. In Briggs, W. R., Jones, R. L. and Walbot, V. (eds.) Annual Review of Plant Physiology, Annual Reviews, Inc., California, 37, 439-466. 
HOLT, L. M., ASTIN, R. AND PAYNE, P. I. 1981. Structural and genetical studies on the high-molecular-weight subunits of wheat glutenin. Part 2. Relative isoelectric points determined by two-dimensional fractionation in polyacrylamide gels. Theor. Appl. Genet., 60, 237-243.

KASARDA, D. D., BERNARDIN, J. E. AND NIMMO, C. C. 1976. Wheat proteins, In Advances in Cereal Science and Technology, Pomeranz, Y. (ed.). American Association of Cereal Chemists, St. Paul. Minn, pp. 158-236.

LAW, C. N. and PAYNE, P. I. 1983. Genetical aspects of breeding for improved grain protein content and type in wheat. $J$. Cereal Sci., 1, 79-93.

MOONEN, J. H. E. AND ZEVEN, A. C. 1985. Association between high molecular weight subunits of glutenin and breadmaking quality in wheat lines derived from backcrosses between Triticum aestivum and Triticum speltoides. J. Cereal Sci., 3, 97-101.

NEVO, E., GOLENBERG, E., BEILES, A., BROWN, A. D. H. AND ZOHARY, D. 1982. Genetic diversity and environmental associations of wild wheat, Triticum dicoccoides, in Israel. Theor. Appl. Genet., 62, 241-254.

ORTH, R. A. AND BUSHUK, w. 1974. Studies of glutenin. VI. Chromosomal location of genes coding for subunits of glutenin of common wheat. Cereal Chemistry, 51, 118-126.

PAYNE, P. I. AND CORFIELD, K. G. 1979. Subunit composition of wheat glutenin proteins, isolated by gel filtration in a dissociating medium. Planta, 145, 83-88.

PAYNE, P. I. AND LAWRENCE, G. J. 1983. Catalogue of alleles for the complex gene loci, Glu-A1, Glu-B1 and Glu-D1 which code for high-molecular-weight subunits of glutenin in hexaploid wheat. Cereal Res. Comm., 11, 29-36.

PAYNE, P. I., CORFIELD, K. G. AND BLACKMAN, J. A. 1979. Identification of a high-molecular-weight subunit of glutenin whose presence correlates with bread-making quality in wheats of related pedigree. Theor. Appl. Genet., $55,153-159$.

PAYNE, P. I., CORFIELD, K. G., HOLT, L. M. AND BLACKMAN, J. A. 1981 a. Correlations between the inheritance of certain high-molecular weight subunits of glutenin and breadmaking quality in progenies of six crosses of bread wheat. J. Sci. Food Agric., 32, 51-60.
PAYNE, P. I., HOLT, L. M. AND LAW, C. N. $1981 b$. Structural and genetical studies on the high-molecular-weight subunits of wheat glutenin. Theor. Appl. Genet., 60, 229-236.

PAYNE, P. I., HOLT, L. M., WORLAND, A. J. AND LAW, C. N. 1982. Structural and genetical studies on the highmolecular-weight subunits of wheat glutenin. Part 3 . Telocentric mapping of the subunit genes on the long arms of the homoeologous group 1 chromosomes. Theor. Appl. Genet., 63, 129-138.

PAYNE, P. I., HOLT, L. M., THOMPSON, R. D., BARTELS, D., HARBERD, N. P., HARRIS, P. A. AND LAW, C. N. 1983. The high-molecular weight subunits of glutenin: classical genetics, molecular genetics and the relationship to breadmaking quality. Proc. 6th Int. Wheat Genet. Symp., Kyoto, Japan, pp. 827-834.

ROZEK, C. E. AND DAVIDSON, N. 1986. Differential processing of RNA transcribed from the single-copy Drosophila myosin heavy chain gene produces four mRNAs that encode two polypeptides. Proc. Natl. Acad. Sci. U.S.A. 83, 2128-2132.

SHEWRY, P. R., FIELD, J. M., FAULKS, A. J., PARMAR, S. AND MIFLIN, P. J. 1984. The purification and N-terminal amino acid sequence analysis of the high molecular weight gluten polypeptides of wheat. Biochimica Biophysica Acta, 788, 23-34.

SUGIYAMA, T., RAFAlSKI, A., PETERSON, D. AND SOll, D. 1985. A wheat HMW glutenin subunit gene reveals a highly repeated structure. Nucl. Acids Res., 13, 8729-8737.

THOMPSON, R. D., BARTELS, D., HARBERD, N. P. AND FLAVELL, R. B. 1983. Characterization of the multigene family coding for HMW glutenin subunits in wheat using cDNA clones. Theor. Appl. Genet., 67, 87-96.

THOMPSON, R. D., BARTELS, D. AND HARBERD, N. P. 1985. Nucleotide sequence of a gene from chromosome 1D of wheat encoding a HMW glutenin subunit. Nucl. Acids Res., $13,6833-6846$. 